\title{
Silver nanoparticles (AgNPs) biosynthesized using pod extract of Cola nitida enhances antioxidant activity and phytochemical composition of Amaranthus caudatus Linn
}

\author{
Luqmon Azeez $^{1} \cdot$ Agbaje Lateef $^{2} \cdot$ Segun A. Adebisi ${ }^{1}$
}

Received: 9 November 2016/ Accepted: 10 January 2017/Published online: 17 January 2017

(C) The Author(s) 2017. This article is published with open access at Springerlink.com

\begin{abstract}
This study investigates the influence of different concentrations of AgNPs biologically synthesized using pod extract of Cola nitida on antioxidant activity, phenolic contents, flavonoid contents and compositions of Amaranthus caudatus L. AgNPs of 25, 50, 75, 100 and $150 \mathrm{ppm}$ were utilized in growing A. caudatus while water was used as control. Delayed germination for two days was observed for A. caudatus grown with $150 \mathrm{ppm}$ of AgNPs, while others showed no difference. There were 43.3, 38.7, 26.7 and $6.48 \%$ improvements in the 2,2-diphenyl-1picrylhydrazyl (DPPH) antioxidant activity of A. caudatus grown with 25, 50, 75 and $100 \mathrm{ppm}$ of AgNPs, respectively, compared to control. Antioxidant activity of $A$. caudatus grown with AgNPs reduced with increase in the concentrations of AgNPs. A. caudatus grown with $50 \mathrm{ppm}$ of AgNPs was the most potent with the least $\mathrm{IC}_{50}$ of $0.67 \mathrm{mg} / \mathrm{ml}$. Significant improvements obtained for phenolic and flavonoid contents grown with AgNPs were concentration dependent. Enhancements of 21.9, 68.19, and $1.98 \%$ in phenolic contents were achieved in treatments with 25, 50 and 75 ppm AgNPs, respectively, while $32.58,35.80$, and $7.20 \%$ improvement in flavonoids were obtained for 25, 50 and $100 \mathrm{ppm}$ treatments, respectively. Kaempferol and quercetin were the most abundant flavonoids in A. caudatus treated with $50 \mathrm{ppm}$ of AgNPs,
\end{abstract}

Luqmon Azeez

azeez012000@yahoo.com

1 Department of Chemical Sciences, Osun State University, Osogbo, Nigeria

2 Nanotechnology Research Group (NANO+), Laboratory of Industrial Microbiology and Nanobiotechnology, Department of Pure and Applied Biology, Ladoke Akintola University of Technology, PMB 4000, Ogbomoso, Nigeria showing the highest flavonoid composition. This further confirms A. caudatus grown with $50 \mathrm{ppm}$ of AgNPs as the most potent. This study has shown that concentration-dependent AgNPs can be used to boost antioxidant activity and phytochemical contents of vegetables.

Keywords Amaranthus caudatus - Silver nanoparticles . Inhibitory concentration - Antioxidant activity .

Phytochemicals

\section{Introduction}

The interest and dependence on vegetables for consumption are attributable to their nutritional importance and health-promoting ability (Navarro et al. 2006; Girija et al. 2011). The ability of vegetables to prevent diseases has been attributed to the various antioxidants contained in them. Vegetables are good sources of natural antioxidants, such as carotenoids, vitamins, polyphenols, flavonoids and anthocyanins which are effective in quenching singlet oxygen and scavenging free radical, thereby preventing oxidation of biomolecules. This consequently prevents incidences of degenerative diseases like atherosclerosis, cancer and heart diseases (Olajire and Azeez 2011; Chandra et al. 2014; Leonov et al. 2015; Li et al. 2015).

Amaranthus caudatus Linn (A. caudatus L.) commonly called Amaranth is an herbaceous plant belonging to Amaranthaceae family. It is a leafy edible vegetable known as "Efotete" in Yoruba (Olajire and Azeez 2011). It cleanses the blood and is used to treat kidney disease and jaundice. It possesses antioxidant, anti-atherosclerotic, anti-helminthic, antimicrobial, anti-cancer, anti-inflammatory, anti-diabetic and antipyretic properties which are due to its high polyphenolic contents (Ashok Kumar et al. 
2011; Girija et al. 2011; Venskutonis and Kraujalis 2013; Miraj 2016).

Humans are continuously exposed to foreign materials and coupled with the inability to properly metabolize these foreign materials, free radicals are thus generated (Olajire and Azeez 2011). Free radicals' production has been linked to oxidation of biomolecules which can be prevented by consumption of vegetables such as A. caudatus considering its antioxidant potential (Medhe et al. 2014; Miraj 2016), but increasing human population with attendant generation of wastes has affected available portion of land for cultivation of vegetables. Thus, there is need to develop methods for boosting phytonutrients of few available vegetables to serve large population of human.

Recent studies have shown that quality of vegetables can be improved with the introduction of nanoparticles during cultivation due to their easy translocation within the plant system and preservation stages. Nanosilvers either chemically or biologically synthesized have unequalled properties, and have gained prominence because of their anticancer, antimicrobial, antibacterial, larvicidal, antioxidant antiparasitic, anticoagulant, thrombolytic and antifungal properties (Rajakumar and Rahuman 2011; Jayaseelan et al. 2011; Sukirtha et al. 2012; Zahir and Rahuman 2012; Raliya et al. 2015; Azeez et al. 2016; Lateef et al. 2016a, b, c, d; Ojo et al. 2016). Due to these properties nanosilvers have been used in therapeutics, and applied in manufacturing of plastics, textile, healthcare products and electrical appliances (Gengan et al. 2013; Schlich and Hund-Rinke 2015; Lateef et al. 2016e).

Furthermore, nanoparticles have been reported to modulate improvement in antioxidant activities of biomolecules as reported in several studies. Shah et al. (2015) reported the use of guar gum-based AgNPs to retain and improve antioxidant activities of Kinnow fruits. Likewise, Medhe et al. (2014) reported the enhancement of antioxidant properties of 3,6-dihydroxylflavanone when embedded in gold nanoparticles. A review by Li et al. (2015) highlighted that nanoparticles enhanced absorption and bioavailability of phenolic compounds when used as nanocarriers for encapsulation of bioactive compounds. Raliya et al. (2015) reported increase in antioxidant activity and lycopene contents of tomatoes grown with zinc and titanium nanoparticles. Khodakovskaya et al. (2013) reported improved seed growth, and germination when tomato seeds were grown with carbon nanotubes, while Narendhran et al. (2016) reported increased root and shoot lengths, photosynthesis pigment content and amount of carbohydrate when Sesamum indicum were grown with biologically synthesized zinc nanoparticles (BZnO). Sharma et al. (2012) reported improvements in weight, root, shoot, vigor index, antioxidant activity, and reduction in malondialdehyde, and hydrogen peroxide levels when Brassica juncea seedlings were treated with AgNPs for seven days.

These studies have shown that nanoparticles can boost antioxidant capacity of vegetables, but nanoparticles used in the previous studies were chemically synthesized and some have been found to be toxic to plant germination and growth (Remedios et al. 2012; Narendhran et al. 2016). Chemical method of synthesis is less eco-friendly and costly compared to biological (green) synthesis. Green synthesis of nanoparticles offers better advantages to other synthetic routes through the biofabrication of biocompatible, less toxic and eco-friendly nanoparticles (Hasan 2015; Adelere and Lateef 2016; Azeez et al. 2016; Lateef et al. 2016e, f; Pavya et al. 2016).

Therefore, in this study, biologically synthesized AgNPs from kola nut (Cola nitida) pods was used to grow $A$. caudatus with the aim of boosting its antioxidant potential and polyphenolic contents. In our previous studies, AgNPs have been prepared using pod, seed and seed shell extracts of $C$. nitida with potent biomedical activities (Lateef et al. 2015b, 2016g, 2017). However, until now, there is no report on the use of AgNPs to boost antioxidant potential and polyphenolic contents of A. caudatus.

\section{Materials and methods}

\section{Biosynthesis and characterization of AgNPs}

AgNPs used in this study were biologically synthesized using the pod extract of $C$. nitida as previously reported by Lateef et al. (2016g). The scheme of the synthesis is shown in Fig. 1. The biosynthesized AgNPs were characterized by UV-Vis spectroscopy, Fourier transform infrared spectroscopy (FTIR) and transmission electron microscopy (TEM) following standard procedures (Lateef et al. 2016g).

\section{Planting of A. caudatus with AgNPs}

A. caudatus seeds were procured from a seed vending shop at Oja-Oba market in Osogbo, Osun state Nigeria, and grown with water (A; control) and five different concentrations of AgNPs (25, 50, 75, 100 and $150 \mathrm{ppm})$, designated as $\mathrm{B}, \mathrm{C}, \mathrm{D}, \mathrm{E}$ and $\mathrm{F}$, respectively. These concentrations were prepared from AgNPs stock with serial dilution using tap water. Twelve 7-1 capacity buckets were filled each with $25 \mathrm{~g}$ of $2 \mathrm{~mm}$ wire-mesh filtered soil (two for each group), soaked with solution for each group, followed by the sowing of A. caudatus seeds on the soil. The seeds were watered daily with $20 \mathrm{ml}$ of solution prepared for each group and all groups were subjected to the same 
Fig. 1 Scheme for the biogenic synthesis of AgNPs using the pod extract of $C$. nitida

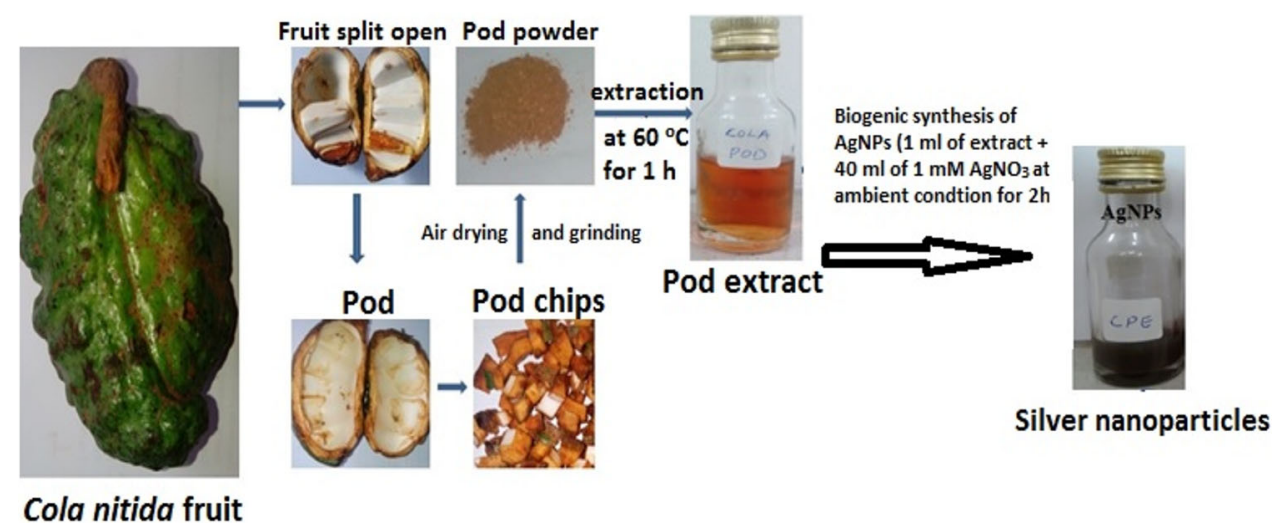

environmental condition. The vegetables were grown for four weeks before harvesting.

\section{Extraction of A. caudatus}

A. caudatus leaves were harvested after four weeks of planting and air dried at room temperature $\left(30 \pm 2{ }^{\circ} \mathrm{C}\right)$. Thereafter, $2 \mathrm{~g}$ of leaves from each group was ground into powder using a Moulinex blender. The extraction of phytochemicals was done twice for each group using $75 \mathrm{ml}$ of $70 \%$ aqueous methanol. The solution was shaken on a magnetic stirrer for $90 \mathrm{~min}$, and afterwards filtered using Whatman No 1 filter paper. The residues from the previous filtration were extracted with $25 \mathrm{ml}$ of $70 \%$ aqueous methanol, shaken for $30 \mathrm{~min}$ and then filtered. The filtrates were combined and concentrated in a rotary evaporator at $75{ }^{\circ} \mathrm{C}$.

\section{Determination of antioxidant activities in $A$. caudatus using DPPH radical scavenging assay}

The free radical scavenging ability of the extract was determined using the stable radical DPPH as previously determined (Lateef et al. 2015a). One $\mathrm{ml}$ of various concentrations $(0.2,0.4,0.6,0.8$, and $1 \mathrm{mg} / \mathrm{ml})$ of the extracts in methanol was added to $4 \mathrm{ml}$ of $0.1 \mathrm{mmol} \mathrm{L}^{-1}$ methanolic solution of DPPH. Blank was obtained by preparing $1 \mathrm{ml}$ of methanol in $4 \mathrm{ml}$ of DPPH. The samples were incubated in the dark at room temperature for $30 \mathrm{~min}$. The absorbance was read at $517 \mathrm{~nm}$ against the prepared blank.

Inhibition of free radicals by DPPH in percent (I\%) was calculated using this formula:

Inhibition $(\%)=\frac{\left(A_{\text {control }}-A_{\text {sample }}\right)}{A_{\text {control }}} \times 100$,

where $A_{\text {control }}$ is the absorbance of the control reaction (containing all reagents except the test compound) and $A_{\text {sample }}$ is the absorbance of the test compound.
Inhibitory concentration at which $50 \%\left(\mathrm{IC}_{50}\right)$ of the free radicals were scavenged was extrapolated from the graph.

\section{Phytochemical contents and composition in $A$. caudatus}

\section{Determination of phenolic contents of $A$. caudatus}

Phenolic content was determined by Folin-Ciocalteu method as reported by Azeez et al. (2012). Exactly $0.5 \mathrm{ml}$ of the methanolic extract was added to $10 \mathrm{ml}$ of distilled water and $2.5 \mathrm{ml}$ of $0.2 \mathrm{~N}$ Folin-Ciocalteu phenol reagent. The mixture was allowed to stand at room temperature for $5 \mathrm{~min}$, and then $2 \mathrm{ml}$ of $2 \%$ sodium carbonate was added. The absorbance of the resulting solution was measured at $780 \mathrm{~nm}$. Quercetin was used as standard for the calibration curve.

\section{Determination of flavonoid contents of $A$. caudatus}

Flavonoid contents were determined as reported by Azeez et al. (2012), whereby $1.5 \mathrm{ml}$ of leaf extract was added to $1.5 \mathrm{ml}$ of $2 \%$ methanolic $\mathrm{AlCl}_{3}$ solution. The mixture was vigorously shaken on orbital shaker for $5 \mathrm{~min}$ at $200 \mathrm{rpm}$ and the absorbance was read at $367 \mathrm{~nm}$ after $10 \mathrm{~min}$ of incubation. Reagent blank using distilled water instead of sample was prepared. Quercetin was used as standard for the calibration curve.

\section{Analysis of flavonoid composition of A. caudatus}

The procedures described by Whitehead et al. (1983), and Provan et al. (1994) and as reported by Azeez et al. (2015) were used for the analysis of flavonoid composition in $A$. caudatus. The composition of flavonoid in leaf extracts was analyzed using gas chromatography coupled with flame ionization detector (GC-FID). Exactly $1 \mu \mathrm{l}$ of each solution was injected into GC (Hewlett-Packard Model 5890, USA) 
with FID which has HP-1 column $(30 \mathrm{~m} \times 0.25 \mu \mathrm{m} \times 0.25 \mathrm{~mm}$ id $)$, nitrogen carrier gas, a detector section temperature of $320{ }^{\circ} \mathrm{C}$ and a split ratio (20:1) mode inlet Section $\left(250^{\circ} \mathrm{C}\right)$. The column was initially held at $60{ }^{\circ} \mathrm{C}$ for $5 \mathrm{~min}$ and then increased at $15^{\circ} \mathrm{C} /$ min for $15 \mathrm{~min}$, maintained for $1 \mathrm{~min}$ and further increased at $10{ }^{\circ} \mathrm{C} / \mathrm{min}$ for $4 \mathrm{~min}$ held for $2 \mathrm{~min}$. Flavonoid compositions obtained for leaf extracts were compared with their standards

\section{Statistical analysis}

Results of phenolic and flavonoid contents are expressed as mean \pm standard deviation of three replicates and were subjected to one-way ANOVA using SPSS 17 version. Significant differences were tested at $p<0.05$.

\section{Results}

\section{Biosynthesized AgNPs}

As earlier reported, the pod extract of $C$. nitida biosynthesized dark brown AgNPs, with surface plasmon resonance obtained at $431.5 \mathrm{~nm}$ (Fig. 2; Lateef et al. 2016g). The nearly spherical-shaped particles had size range of 12-80 nm (Fig. 2), and were formed as a result of the activities of proteinous molecules in the pod extract, which were responsible for the bioreduction of $\mathrm{Ag}^{+}$to $\mathrm{Ag}^{0}$, capping and stabilization of the AgNPs. The selected area electron diffraction (SAED) pattern showed that the particles were crystalline in nature, with predominant presence of Ag metal in the energy-dispersive X-ray (EDX) spectra.

\section{Impact of AgNPs on germination of A. caudatus seeds}

Germination was observed after two days except for $A$. caudatus that was grown with $150 \mathrm{ppm}$ of AgNPs which started growth on the fourth day. A. caudatus grown with 100 and $150 \mathrm{ppm}$ had reduced vegetable population with some having yellow leaves and stunted growth.

\section{Antioxidant activities}

The results of DPPH radical scavenging properties of leaf extracts of $A$. caudatus grown with different concentrations of AgNPs are as shown in Fig. 3. The trend ranging from the highest antioxidant activities to the lowest is of the order $\mathrm{B}>\mathrm{C}>\mathrm{D}>\mathrm{E}>\mathrm{A}>\mathrm{F}$. Significant improvements in antioxidant activity were recorded for A. caudatus grown with different concentrations of AgNPs except $150 \mathrm{ppm}$ AgNPs which had lower antioxidant activity than $A$. caudatus grown with water (control). There were 43.3, 38.7, 26.7 , and $6.48 \%$ improvements in antioxidant activities of $\mathrm{B}, \mathrm{C}, \mathrm{D}$ and $\mathrm{E}$, respectively, in relation to the control sample that was treated with water. However, it was observed that with increase in the concentration of AgNPs, the percentage improvement in the antioxidant activities of leaf extracts of $A$. caudatus reduces. The $\mathrm{IC}_{50}$ values of the leaf extracts of $A$. caudatus leaf were obtained as follows:
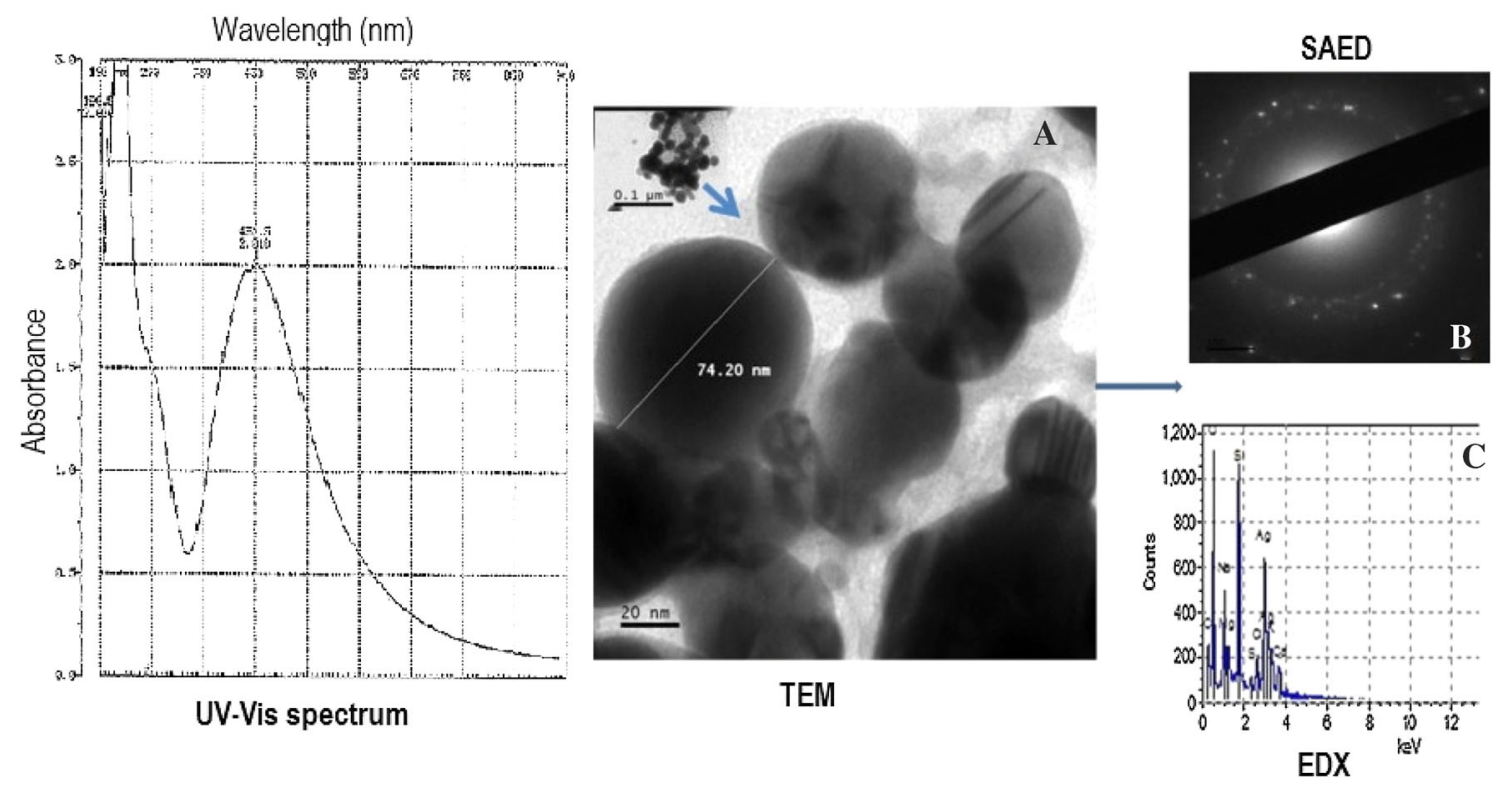

Fig. 2 The UV-Vis spectrum, TEM micrographs, SAED pattern and EDX spectra of the biosynthesized AgNPs 


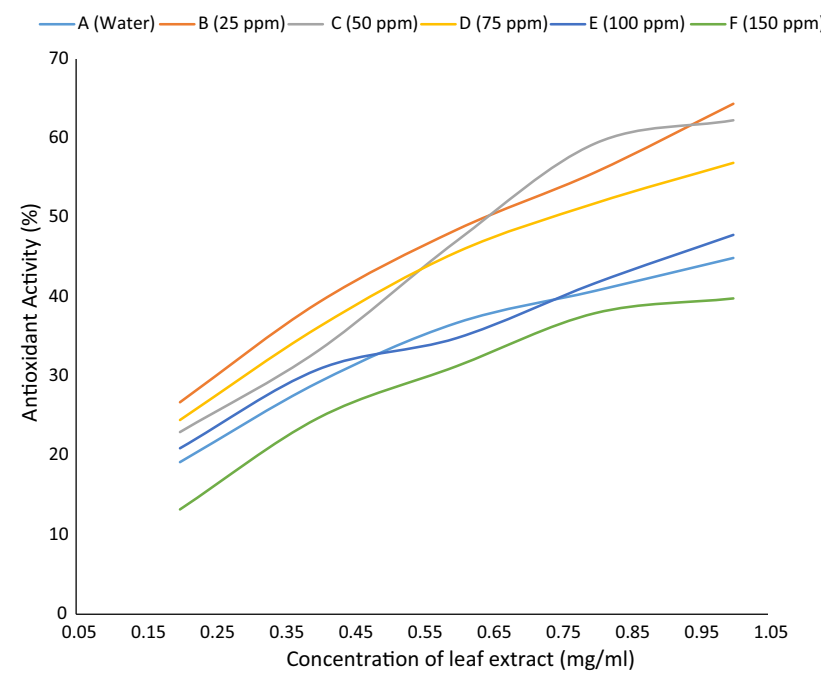

Fig. 3 Antioxidant activity of A. caudatus leaf extract grown with different concentrations of AgNPs

$\mathrm{C}(0.67 \mathrm{mg} / \mathrm{ml})>\mathrm{B}(0.72 \mathrm{mg} / \mathrm{ml})>\mathrm{D}(1.02 \mathrm{mg} / \mathrm{ml})>\mathrm{E}$ $(1.15 \mathrm{mg} / \mathrm{ml})>\mathrm{A}(1.27 \mathrm{mg} / \mathrm{ml})>\mathrm{F}(1.38 \mathrm{mg} / \mathrm{ml})$.

\section{Phytochemical contents and composition}

\section{Phenolic and flavonoid contents}

The results of phenolic and flavonoid contents of $A$. caudatus grown with different concentrations of AgNPs are as shown in Table 1 . The phenolic content abundance ranged from 29.61 to $74.35 \mathrm{mg}$ quercetin/g of extract in the order $\mathrm{C}>\mathrm{B}>\mathrm{D}>\mathrm{A}>\mathrm{E}>\mathrm{F}$. There were 21.19, 68.18 and $1.98 \%$ improvement in the phenolic contents of B, C and D compared to control (A), while there were 3.79 and $46.68 \%$ reduction in phenolic contents in $\mathrm{E}$ and $\mathrm{F}$ compared to $\mathrm{A}$.

The results of abundance of flavonoids in A. caudatus grown with different concentrations of AgNPs ranged from 54.19 to $170.93 \mathrm{mg}$ quercetin/g of extract in the following order; $\mathrm{C}>\mathrm{B}>\mathrm{E}>\mathrm{A}>\mathrm{D}>\mathrm{F}$. There were 32.58, 35.80, and $7.20 \%$ improvement in the flavonoids of $\mathrm{C}, \mathrm{B}$ and $\mathrm{E}$ compared to A, while 44.11 and $45.92 \%$ reduction were obtained for flavonoid contents in D and F, respectively, compared to A.

In relation to the control sample, A. caudatus grown with 25 and $50 \mathrm{ppm}$ of AgNPs (B and C) had significantly higher phenolic contents, while those treated with 75 and 100 ppm of AgNPs had comparable phenolic contents. However, A. caudatus grown with $150 \mathrm{ppm}$ of AgNPs exhibited significantly lower phenolic contents compared with the control. In addition, contents of flavonoids in A. caudatus treated with 25 and $50 \mathrm{ppm}$ of AgNPs were significantly higher than the control sample, while treatment with 100 ppm of AgNPs depicted comparable flavonoids content with the control. Conversely, treatments with 75 and 150 ppm of AgNPs produced significantly lower flavonoids contents compared with the control.

\section{Flavonoid compositions}

Flavonoid compositions of $A$. caudatus grown with water, and AgNPs (50, 100 and $150 \mathrm{ppm}$ ) are presented in Table 2. A. caudatus grown with 50 ppm of AgNPs had highest flavonoid composition of $334.80 \mathrm{mg} / 100 \mathrm{~g}$, which was followed by treatment with $100 \mathrm{ppm}$ of AgNPs (194.99 mg/100 g), water $(117.25 \mathrm{mg} / 100 \mathrm{~g}$ ) and $150 \mathrm{ppm}$ of AgNPs (88.02 mg/ $100 \mathrm{~g})$. Kaempferol was the most abundant flavonoid that was present in the leaf extract followed by quercetin, naringin, rutin, catechin, myricetin and epicatechin. Comparing the concentrations of most abundant flavonoids (kaempferol and quercetin) in the treatments with the control, there were 232.02 and $52.63 \%$ improvement in kaempferol of $A$. caudatus treated with 50 and 100 ppm of AgNPs, respectively, while 113.48 and $97.04 \%$ improvement in quercetin concentrations were achieved for the treatments, respectively.

\section{Discussion}

Phytochemicals have been reported to offer protection against cancer, cardiovascular diseases and diabetes due to their anti-cancer, anti-inflammatory, and anti-diabetic

Table 1 Phenolic and flavonoid contents of A. caudatus grown with different concentrations of AgNPs

\begin{tabular}{lll}
\hline Concentration & Phenolic content $(\mathrm{mg}$ quercetin/g of extract) & Flavonoid content (mg quercetin/g of extract) \\
\hline Water (A) & $101.63 \pm 0.58^{\mathrm{a}}$ & $54.75 \pm 0.35^{\mathrm{a}}$ \\
$25 \mathrm{ppm}(\mathrm{B})$ & $123.17 \pm 4.04^{\mathrm{b}}$ & $72.59 \pm 1.91^{\mathrm{b}}$ \\
$50 \mathrm{ppm}(\mathrm{C})$ & $170.93 \pm 2.33^{\mathrm{c}}$ & $74.35 \pm 0.14^{\mathrm{b}}$ \\
$75 \mathrm{ppm}$ (D) & $103.65 \pm 1.11^{\mathrm{a}}$ & $32.24 \pm 0.81^{\mathrm{c}}$ \\
$100 \mathrm{ppm}(\mathrm{E})$ & $97.77 \pm 2.52^{\mathrm{a}}$ & $58.69 \pm 1.67^{\mathrm{a}}$ \\
$150 \mathrm{ppm}(\mathrm{F})$ & $54.19 \pm 0.83^{\mathrm{d}}$ & $29.61 \pm 1.25^{\mathrm{c}}$
\end{tabular}

Each value is expressed as mean \pm standard deviation $(n=3)$

Values with different superscripts along the same column are significantly different $(p<0.05)$

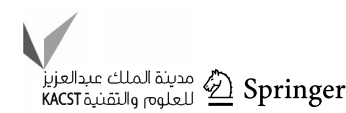


Table 2 Flavonoid composition of A. caudatus grown with different concentrations of AgNPs

\begin{tabular}{lllll}
\hline Flavonoid (mg/100 g) & Water (control) & 50 & AgNPs (ppm) 100 & 150 \\
\hline Catechin & 0.34 & 0.14 & 0.21 & 0.03 \\
Quercetin & 40.81 & 87.12 & 80.41 & 30.88 \\
Kaempferol & 65.53 & 217.04 & 100.02 & 52.82 \\
Naringin & 8.49 & 21.44 & 12.03 & 4.29 \\
Epicatechin & $1.2 \mathrm{e}-3$ & $2.2 \mathrm{e}-3$ & $3.2 \mathrm{e}-3$ & $2.8 \mathrm{e}-4$ \\
Myricetin & $5.67 \mathrm{e}-2$ & 1.02 & $7.45 \mathrm{e}-2$ & $3.4 \mathrm{e}-3$ \\
Rutin & 2.02 & 8.04 & 2.24 & $\mathrm{ND}$ \\
Total & 117.25 & 334.80 & 194.99 & 88.02 \\
\hline
\end{tabular}

$N D$ not detected

properties (Chandra et al. 2014; Leonov et al. 2015). Epidemiological studies have also strongly shown that consumption of vegetables positively correlated to prevention of degenerative diseases ( $\mathrm{Li}$ et al. 2015), while studies have established high correlation between antioxidant activity and phytochemicals of vegetables (Olajire and Azeez 2011). However, the composition and concentration of phytochemicals in vegetables are influenced by many factors, such as soil condition (chemical form, bioavailability and mobility), photosynthesis pigment contents and climatic conditions (Chandra et al. 2014; Leonov et al. 2015; Li et al. 2015; Schlich and Hund-Rinke 2015). A novel way to improve the quantity and quality of phytochemicals in vegetables is through the intervention of nanobiotechnology, which was undertaken in this study. Nanoparticles have been reported to improve mineral absorption, boost light absorption and increase water uptake by plants (Khodakovskaya et al. 2013; Raliya et al. 2015). There is growing trend in the deployment of nanobiotechnology in agriculture to increase productivity and improve the quality of agricultural products.

In this study, it was observed that $A$. caudatus grown with $150 \mathrm{ppm}$ of AgNPs had delayed seed germination for two days, whereas A. caudatus grown with other concentrations had germinated, indicating that lower concentrations of AgNPs did not pose any adverse effect on seed germination. Yellowing of leaves and decreased vegetable population recorded for $A$. caudatus treated with $150 \mathrm{ppm}$ of AgNPs could be as a result of toxicity induced by high concentration. This is in agreement with the report of Yin et al. (2012), in which $40 \mathrm{mg} / \mathrm{L}$ of gum arabic AgNPs significantly reduced the germination rate of Crambe scoparia, while lower concentration had no effects. In addition, high concentration of AgNPs had been reported to prolong lettuce seeds growth and decreased their biomass (Shah and Belozerova 2009). This was equally similar to result obtained by Narendhran et al. (2016), whereby improvements in root and shoot lengths, photosynthesis pigment content and amount of carbohydrate were achieved, when Sesamum indicum seeds were grown with biologically synthesized zinc nanoparticles.

The different concentrations of AgNPs influenced the antioxidant activity and phytochemical contents of $A$. caudatus. The AgNPs used in this study have been found to be highly potent, with higher DPPH scavenging activities than quercetin and $\beta$-carotene (Lateef et al. 2016g). Antioxidant activities of leaf extracts of $A$. caudatus witnessed reduction with increase in the concentration of AgNPs. While the treatment with 150 ppm of AgNPs had the lowest antioxidant activity, A. caudatus grown with $50 \mathrm{ppm}$ of AgNPs was the most potent having the $\mathrm{IC}_{50}$ of $0.67 \mathrm{mg} / \mathrm{ml}$. Significantly higher phenolic and flavonoid contents obtained for AgNPs-grown A. caudatus showed the influence of the nanoparticles on their improved antioxidant activities. While the phenolic contents of $A$. caudatus were linearly improved with increase in the concentration of AgNPs, the effects of treatment with AgNPs on flavonoid contents did not show a regular pattern but nonetheless, it increased with increase in AgNPs concentration except for the treatment that had $150 \mathrm{ppm}$ of AgNPs.

Plants produce phytochemicals for survival, ecosystem adaptation, and defence when faced with environmental stress and infection by pathogenic organisms (Leonov et al. 2015; Shah et al. 2015). This suggests that for A. caudatus grown with AgNPs to tolerate the stress imposed by reconditioning the soil habitat due to the introduction of nanoparticles, it generated more phytochemicals for its survival and defence. A similar result reported by Raliya et al. (2015) showed that zinc and titanium nanoparticles boosted antioxidant activity and phytochemical content (lycopene) of tomato by influencing its mineral absorption. In addition, Kole et al. (2013) reported improved plant biomass, fruit yield and phytomedicinal contents (cucurbitacin-B, lycopene, charantin and insulin) in bitter melon (Momordica charantia) treated with carbon-based nanoparticles, fullerol $\left(\mathrm{C}_{60}(\mathrm{OH})_{20}\right)$. Equally, Sharma et al. 
(2012) reported improvements in antioxidant activity and reduction in malonaldehyde and hydrogen peroxide levels when Brassica juncea seedlings were treated with AgNPs.

Flavonoid composition of A. caudatus showed highest abundance of kaempferol and quercetin in the plant grown with $50 \mathrm{ppm}$ of AgNPs. Kaempferol and quercetin are known for their anti-inflammatory and antioxidant activities. Kaempferol lowers reactive oxygen species level and susceptibility of humans to oxidative stress, while quercetin lowers lipid peroxidation and reduces oxidative damage to biomolecules (Askari et al. 2013; Leonov et al. 2015). The highest potency of $A$. caudatus grown with $50 \mathrm{ppm}$ of AgNPs as obtained for antioxidant activity is further confirmed by the abundance of flavonoids in the treatment. The results obtained in the study underscore the relevance of nanobiotechnology in agriculture to boost the production of crops with improved phytomedicinal contents.

\section{Conclusion}

We have investigated the influence of different concentrations of kola pod mediated-AgNPs on antioxidant activity and phytochemical contents of A. caudatus. Antioxidant activities of $A$. caudatus grown with AgNPs except for the highest concentration of $150 \mathrm{ppm}$ had higher antioxidant activities than $A$. caudatus grown with water only. Phenolic and flavonoid contents of A. caudatus increased with increase in concentrations of AgNPs except for $150 \mathrm{ppm}$ of AgNPs. Kaempferol and quercetin were found to be the most abundant flavonoids in A. caudatus grown with $50 \mathrm{ppm}$ of AgNPs. This study has been able to establish the concentration-dependent application of biologically synthesized AgNPs to boost antioxidant activity and phytochemical contents of vegetables, which is a novel utilization of kola pod mediated-AgNPs to improve these attributes in A. caudatus.

Open Access This article is distributed under the terms of the Creative Commons Attribution 4.0 International License (http:// creativecommons.org/licenses/by/4.0/), which permits unrestricted use, distribution, and reproduction in any medium, provided you give appropriate credit to the original author(s) and the source, provide a link to the Creative Commons license, and indicate if changes were made.

\section{References}

Adelere IA, Lateef A (2016) A novel approach to the green synthesis of metallic nanoparticles: the use of agro-wastes, enzymes and pigments. Nanotechnol Rev 5:567-587

Ashok Kumar BS, Lakshman K, Jayaveera KN, SheshadriShekar D, Narayan Swamy VB, Khan S, Velumurga C (2011) In vitro $\alpha$ - amylase inhibition and antioxidant activities of methanolic extract of Amaranthus caudatus Linn. Oman Med J 26(3):166-170

Askari G, Ghiasvand R, Paknahad Z, Karimian J, Rabiee K, Sharifirad G, Feizi A (2013) The effects of quercetin supplementation on body composition, exercise performance and muscle damage indices in athletes. Int J Prev Med 4:21-26

Azeez L, Adeoye MD, Majolagbe TA, Lawal AT, Badiru R (2012) Antioxidant activity and phytochemical contents of some selected Nigerian fruits and vegetables. Am J Chem 2(4):209-213

Azeez L, Ogundode SM, Ganiyu OT, Oyedeji OA, Tijani KO, Adewuyi SO (2015) Spectra characterization, flavonoid profile, antioxidant activity and antifungal property of Senecio bifrae and its copper complex. Sci Res Essays 10(8):593-599

Azeez MA, Lateef A, Asafa TB, Yekeen TA, Akinboro A, Oladipo IC, Gueguim-Kana EB, Beukes LS (2016) Biomedical applications of cocoa bean extract-mediated silver nanoparticles as antimicrobial, larvicidal and anticoagulant agents. J Clust Sci. doi:10.1007/s10876-016-1055-2

Chandra S, Khan S, Avula B, Lata H, Yang MH, ElSohly MA, Khan IA (2014) Assessment of total phenolic and flavonoid content, antioxidant properties, and yield of aeroponically and conventionally grown leafy vegetables and fruit crops: a comparative study. eCAM 253875. doi:10.1155/2014/253875

Gengan RM, Anand K, Phulukdaree A, Chuturgoon A (2013) A549 lung cell line activity of biosynthesized silver nanoparticles using Albizia adianthifolia leaf. Colloids Surf B 105:87-91

Girija K, Lakshman K, Chandrika U, Ghosh SS, Divya T (2011) Antidiabetic and anti cholesterolemic activity of methanol extracts of three species of Amaranthus. Asian Pac J Trop Biomed $1(2): 133-138$

Hasan S (2015) A review on nanoparticles: their synthesis and types (ISC 2014). Res J Recent Sci 4:1-3

Jayaseelan C, Rahuman AA, Rajakumar G, Kirthi AV, Santhoshkumar T, Marimuthu S, Bagavan A, Kamaraj C, Zahir AA, Elango G (2011) Synthesis of pediculocidal and larvicidal silver nanoparticles by leaf extract from heartleaf moonseed plant, Tinospora cordifolia Miers. Parasitol Res 109:185-194

Khodakovskaya MV, Kim BS, Kim JM, Alimohammadi M, Dervishi E, Mustafa T, Cernigla CE (2013) Carbon nanotubes as plant growth regulators: effects on tomato growth, reproductive system and soil microbial community. Small 9(1):115-123. doi: $10.1002 / \mathrm{smll} .201201225$

Kole C, Kole P, Randunu KM, Choudhary P, Podila R, Ke PC, Rao AM, Marcus RK (2013) Nanobiotechnology can boost crop production and quality: first evidence from increased plant biomass, fruit yield and phytomedicine content in bitter melon (Momordica charantia). BMC Biotechnol 13:37

Lateef A, Ojo SA, Akinwale AS, Azeez L, Gueguim-Kana EB, Beukes LS (2015a) Biogenic synthesis of silver nanoparticles using cell-free extract of Bacillus safensis LAU 13: antimicrobial, free radical scavenging and larvicidal activities. Biologia 70(10):1295-1306

Lateef A, Azeez MA, Asafa TB, Yekeen TA, Akinboro A, Oladipo IC, Ajetomobi FE, Gueguim-Kana EB, Beukes LS (2015b) Cola nitida-mediated biogenic synthesis of silver nanoparticles using seed and seed shell extracts and evaluation of antimicrobial activities. BioNanosci 5:196-205

Lateef A, Akande MA, Azeez MA, Ojo SA, Folarin BI, GueguimKana EB, Beukes LS (2016a) Phytosynthesis of silver nanoparticles (AgNPs) using miracle fruit plant (Synsepalum dulcificum) for antimicrobial, catalytic, anti-coagulant and thrombolytic applications. Nanotechnol Rev 5:507-520

Lateef A, Akande MA, Ojo SA, Folarin BI, Gueguim-Kana EB, Beukes LS (2016b) Paper wasp nest-mediated biosynthesis of

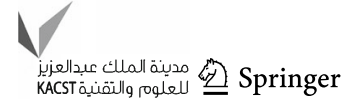


silver nanoparticles for antimicrobial, catalytic, anti-coagulant and thrombolytic applications. 3Biotech 6:140

Lateef A, Ojo SA, Folarin BI, Gueguim-Kana EB, Beukes LS (2016c) Kola nut (Cola nitida) mediated synthesis of silver-gold alloy nanoparticles: antifungal, catalytic, larvicidal and thrombolytic applications. J Clust Sci 27:1561-1577

Lateef A, Ojo SA, Oladejo SM (2016d) Anti-candida, anti-coagulant and thrombolytic activities of biosynthesized silver nanoparticles using cell-free extract of Bacillus safensis LAU 13. Process Biochem 51:1406-1412

Lateef A, Azeez MA, Asafa TB, Yekeen TA, Akinboro A, Oladipo IC, Azeez L, Ojo SA, Gueguim-Kana EB, Beukes LS (2016e) Cocoa pod husk extract-mediated biosynthesis of silver nanoparticles: its antimicrobial, antioxidant and larvicidal activities. J Nanostruct Chem 6(2):159-169

Lateef A, Ojo SA, Elegbede JA (2016f) The emerging roles of arthropods and their metabolites in the green synthesis of metallic nanoparticles. Nanotechnol Rev 5:601-622

Lateef A, Azeez MA, Asafa TB, Yekeen TA, Akinboro A, Oladipo IC, Azeez L, Ajibade SE, Ojo SA, Gueguim-Kana EB, Beukes LS (2016g) Biogenic synthesis of silver nanoparticles using a pod extract of Cola nitida: Antibacterial and antioxidant activities and application as a paint additive. $\mathrm{J}$ Taibah Univ Sci 10:551-562

Lateef A, Ojo SA, Elegbede JA, Azeez MA, Yekeen TA, Akinboro A (2017) Evaluation of some biosynthesized silver nanoparticles for biomedical applications: hydrogen peroxide scavenging, anticoagulant and thrombolytic activities. J Clust Sci. doi:10. 1007/s10876-016-1146-0

Leonov A, Arlia-Ciommo A, Piano A, V Lutchman, Svistkova V, Medkour Y, Titorenko VI (2015) Longevity extension by phytochemicals. Molecules 20:6544-6572

Li Z, Jiang H, Xu C, Gu L (2015) A review: Using nanoparticles to enhance absorption and bioavailability of phenolic phytochemicals. Food Hydrocolloid 43:153-164

Medhe S, Bansal P, Srivastava MM (2014) Enhanced antioxidant activity of gold nanoparticle embedded 3,6-dihydroxyflavone: a combinational study. Appl Nanosci 4:153-161

Miraj S (2016) A Medicinal plant with antioxidant activity in Iranian folk medicine: Amaranthus. Der Pharm Lett 8(14):27-30

Narendhran S, Rajiv P, Sivaraj R (2016) Influence of zinc oxide nanoparticles on growth of Sesamum indicum $\mathrm{L}$. in zinc deficient soil. Int J Pharm Pharm Sci 8(3):365-371

Navarro JM, Flores P, Garrido C, Martinez V (2006) Changes in the contents of antioxidant compounds in pepper fruits at different ripening stages, as affected by salinity. Food Chem 96:66-73

Ojo SA, Lateef A, Azeez MA, Oladejo SM, Akinwale AS, Asafa TB, Yekeen TA, Akinboro A, Oladipo IC, Gueguim-Kana EB, Beukes LS (2016) Biomedical and catalytic applications of gold and silver-gold alloy nanoparticles biosynthesized using cell-free extract of Bacillus safensis LAU 13: antifungal, dye degradation, anti-coagulant and thrombolytic activities. IEEE Trans Nanobiosci 15(5):433-442
Olajire AA, Azeez L (2011) Total antioxidant activity, phenolic, flavonoid and ascorbic acid contents of Nigerian vegetables. Afr J Food Sci Tech 2(2):22-29

Pavya T, Praseetha PK, Rimal Isaac RS (2016) Green synthesis of gold nanoparticles using plant sources for cancer therapy: a review. Res J Pharm Biol Chem Sci 7(5):472-480

Provan GJ, Scobbie L, Chesson A (1994) Determination of phenolic acids in plant cell walls by microwave digestion. J Sci Food Agric 64:63-65

Rajakumar G, Rahuman AA (2011) Larvicidal activity of synthesized silver nanoparticles using Eclipta prostrata leaf extract against filariasis and malaria vectors. Acta Trop 118:196-203

Raliya R, Nair R, Chavalmane S, Wang W-N, Biswas P (2015) Mechanistic evaluation of translocation and physiological impact of titanium dioxide and zinc oxide nanoparticles on the tomato (Solanum lycopersicum L.) plant. Metallomics 7:1584-1594

Remedios C, Rosario F, Bastos V (2012) Environmental nanoparticles interactions with plants: morphological, physiological, and genotoxic aspects. J Bot 751686:8. doi:10.1155/2012/751686

Schlich K, Hund-Rinke K (2015) Influence of soil properties on the effect of silver nanomaterials on microbial activity in five soils. Environ Pollut 196:321-330

Shah V, Belozerova I (2009) Influence of metal nanoparticles on the soil microbial community and germination of lettuce seeds. Water Air Soil Pollut 197:143-148

Shah SWA, Jahangir M, Qaisar M, Khan SA, Mahmood T, Saeed M, Farid A, Liaquat M (2015) Storage stability of Kinnow fruit (Citrus reticulata) as affected by $\mathrm{CMC}$ and guar gum-based silver nanoparticle coatings. Molecules 20:22645-22661

Sharma P, Bhatt D, Zaidi MG, Saradhi PP, Khanna PK, Arora S (2012) Silver nanoparticle mediated enhancement in growth and antioxidant status of Brassica juncea. Appl Biochem Biotechnol 167:2225-2233

Sukirtha R, Priyanka KM, Antony JJ, Thangam R, Kamalakkannan S, Gunasekaran P, Krishnan M, Achiraman S (2012) Cytotoxic effect of green synthesized silver nanoparticles using Melia azedarach against in vitro HeLa cell lines and lymphoma mice model. Process Biochem 47:273-279

Venskutonis PR, Kraujalis P (2013) Nutritional components of amaranth seeds and vegetables: a review on composition, properties, and uses. Compr Rev Food Sci Food Saf 12:318-412

Whitehead D, Dibb CH, Hartley RD (1983) Bound phenolic compounds in water extracts of soil, plant roots and leaf litter. Soil Biol Biochem 15:133-136

Yin L, Colman BP, McGill BM, Wright JP, Bernhardt ES (2012) Effects of silver nanoparticle exposure on germination and early growth of eleven wetland plants. PLoS One 7(10):e47674. doi:10.1371/journal.pone.0047674

Zahir AA, Rahuman AA (2012) Evaluation of different extracts and synthesised silver nanoparticles from leaves of Euphorbia prostrata against Haemaphysalis bispinosa and Hippobosca maculata. Vet Parasitol 187:511-520 